\title{
Screen based activity sebagai faktor risiko kegemukan pada anak prasekolah di Kota Yogyakarta
}

\author{
Screen based activity (SBA) as risk factor of obesity among preschool children in Yogyakarta city
}

Neni Pangesti ${ }^{1}$, I Made Alit Gunawan ${ }^{2}$, Madarina Julia ${ }^{3}$

${ }^{1}$ Jurusan Gizi Politeknik Kesehatan Kementerian Kesehatan Kendari

${ }^{2}$ Jurusan Gizi Politeknik Kesehatan Kementerian Kesehatan Yogyakarta

${ }^{3}$ Departemen Ilmu Kesehatan Anak, Fakultas Kedokteran Universitas Gadjah Mada / Rumah Sakit Umum Pusat Dr. Sardjito

\begin{abstract}
Background: Obesity in children increased health risk and the high cost of treatment of obesity. Extensive screen based activity (SBA) are sedentary behavior which is contributing to childhood obesity. Objective: to analyze the risk of duration of SBA with obesity among preschool children in Yogyakarta City. Method: The study design was case-control study between obese and nonobese preschool children. A hundred and one pairs (obese and non-obese) subjects aged 3-5 years old who enrolled in preschools in Yogyakarta was obtained from screening. The school was selected using Probability Proportional to Size method. The case and control were matching by age and gender. Obesity was defined by WHZ-score $>2$ SD. Preschool Physical Activity Questionnaire (PrePAQ) was used to collect the information on duration of SBA. Data duration SBA asked at weekdays and weekend. Data was analyzed using t-test. Results: children duration of SBA at weekend and parents duration of SBA were not statistically associated with obesity occurrence in children $(p>0,05)$. Obese children spent 48 minutes longer engaged in SBA compared to the non-obese children in weekdays.Conclusion: Children duration of SBA at weekdays could increase the risk of obesity occurrence among preschool children in Yogyakarta.
\end{abstract}

KEY WORDS: obesity; preschool; screen based activity

\begin{abstract}
ABSTRAK
Latar belakang: Kegemukan meningkatkan risiko kesehatan dan biaya berobat akibat obesitas. Salah satu penyebab kegemukan anak adalah gaya hidup kurang gerak yaitu screen based activity (SBA). Tujuan: Menganalisis besar faktor risiko pengenalan dini dan lama waktu SBA dengan kegemukan anak prasekolah di Kota Yogyakarta. Metode: Desain penelitian kasus kontrol pada anak prasekolah yang gemuk dan tidak gemuk. Sejumlah 101 pasang anak usia 3-5 tahun yang diperoleh dari hasil skrining di Pendidikan Anak Usia Dini (PAUD) Kota Yogyakarta. Pengambilan subjek sekolah melalui metode probability proportional to size (PPS). Subjek kasus dan kontrol diambil dengan matching jenis kelamin dan umur. Kegemukan didefinisikan sebagai z-skor BB/TB > 2 SD. Data pengenalan dini dan SBA dikumpulkan menggunakan Preschool Physical Activity Questionnaire (PrePAQ). Analisis data menggunakan t-test. Hasil: Lama waktu SBA anak saat hari libur dan lama waktu SBA orang tua tidak berhubungan dengan kejadian obesitas ( $>00,05)$. Anak gemuk melakukan SBA lebih lama 48 menit saat hari sekolah dibanding anak normal. Simpulan: Lama waktu SBA anak saat hari sekolah meningkatkan peluang terjadinya kegemukan pada anak prasekolah di Kota Yogyakarta.
\end{abstract}

KATA KUNCI: kegemukan; prasekolah; screen based activity

\section{PENDAHULUAN}

Kegemukan pada masa kanak-kanak dihubungkan dengan konsekuensi psikososial dan serangkaian masalah kesehatan yang kemungkinan akan terus berlangsung hingga masa dewasa dan menyebabkan kematian dini (1).
Balita termasuk kategori gemuk jika z-skor berat badan menurut tinggi badan (BB/TB) standar World Health Organization (WHO) $2005>2,0$ SD (2). Prevalensi anak

Korespondensi: Neni Pangesti, Jurusan Gizi Politeknik Kesehatan Kementerian Kesehatan Kendari, Jl. Pattimura 45, Kendari,e-mail: neni.pangesti@gmail. com 
gemuk berdasarkan z-skor BB/TB di Yogyakarta sebesar $14 \%$ sedangkan tahun 2014, status gizi gemuk pada balita di Kota Yogyakarta sebesar 8,98\% $(3,4)$.

Salah satu penyebab kegemukan anak adalah gaya hidup kurang gerak yaitu kurang aktivitas fisik, seperti menonton televisi (TV) dan bermain komputer (screen based activity) lebih dari 2 jam/hari (5). Semakin lama waktu menonton TV dihubungkan dengan risiko komposisi tubuh yang tidak sehat dan peningkatan IMT (6). Selain itu, TV di kamar tidur dihubungkan dengan waktu penggunaan screen based activity (SBA) lebih banyak. Anak dengan TV di kamar tidur lebih cenderung menjadi overweight (7). Selain itu, anak yang menonton TV $\geq 3$ jam/hari cenderung $48 \%$ menjadi lebih obes dibanding anak yang menonton TV $<1$ jam/hari. Screen based activity, terutama TV dihubungkan dengan rendahnya konsumsi sayur dan buah serta tingginya konsumsi camilan tinggi kalori, makanan cepat saji (8), dan minuman kemasan tinggi gula (9). Iklan makanan dan minuman yang ditayangkan selama anak menonton TV berkontribusi pada kegemukan anak (10). Peningkatan asupan energi saat SBA karena ketidaktepatan pilihan makanan yaitu konsumsi makanan ringan dengan densitas energi tinggi (makanan tinggi tambahan gula dan lemak) dan kurangnya kontrol pada jumlah porsi yang dimakan (1).

Penelitian yang dilakukan oleh di Amerika pada anak usia 8-16 tahun yang menonton TV 4 jam/hari memiliki indeks massa tubuh (IMT) lebih besar dibanding yang menonton TV kurang dari 2 jam/hari (11). Waktu menonton TV orang tua dihubungkan dengan waktu menonton TV anak. Anak yang tinggal dengan orang tua yang menonton TV lebih dari 2 jam/hari berisiko menonton TV lebih dari 4 jam/hari dibanding yang tidak (12). Hingga saat ini, belum ada penelitian tentang lama waktu SBA sebagai faktor risiko kegemukan pada anak prasekolah di Kota Yogyakarta. Tujuan penelitian ini adalah untuk menganalisis besar faktor risiko lama waktu SBA dengan kegemukan anak prasekolah di Kota Yogyakarta.

\section{BAHAN DAN METODE}

Penelitian ini berdesain kasus kontrol yang dilaksanakan pada bulan Juli - Oktober 2015 di Kota Yogyakarta. Subjek yang diinginkan adalah anak usia
3-5 tahun yang bersekolah di Kota Yogyakarta. Subjek penelitian berasal dari 53 Pendidikan Anak Usia Dini (PAUD) di Kota Yogyakarta yang dipilih dengan metode probability proportional to size (PPS). Penelitian diawali dengan skrining status gizi yang memperoleh 1.320 anak sesuai dengan kriteria inklusi. Anak berstatus gizi normal sejumlah 1.145 dan berstatus gizi gemuk sejumlah 175 anak. Setelah dilakukan matching jenis kelamin dan usia, terdapat 168 anak berstatus gizi normal dan 158 anak gemuk yang mengembalikan informed consent. Hanya 107 pasang orang tua yang setuju melakukan wawancara dengan menandatangani informed consent. Sejumlah 6 subjek penelitian pada kelompok kasus tidak menyelesaikan wawacara hingga tuntas sehingga terpilih 101 pasang kasus dan kontrol menjadi subjek penelitian. Anak yang terpilih menjadi subjek penelitian diberi lembar persetujuan untuk diisi orang tua mereka.

Besar subjek dihitung dengan rumus derajat kepercayaan (z $\alpha / 2)$ 95\%; kekuatan uji sebesar 0,842; dan OR sebesar 1,65 dengan perbandingan kasus dan kontrol 1:1, maka jumlah subjek minimal yang dibutuhkan adalah 101 pasang anak. Rincian subjek penelitian sebanyak 108 anak laki-laki dan 94 anak perempuan. Kriteria inklusi subjek kasus adalah berusia 3-5 tahun, bersekolah di PAUD non-full day di Kota Yogyakarta, dan berstatus gizi gemuk (berdasarkan z-skor BB/TB standar WHO 2005 $>2 \mathrm{SD}$ ). Kontrol diambil dari anak berstatus gizi normal (berdasarkan z-skor BB/TB standar WHO $2005 \leq 2$ SD) dengan matching usia dan jenis kelamin.

Data yang diperoleh merupakan data primer yang berasal dari hasil penimbangan saat skrining dan wawancara dengan orang tua. Pengambilan data dilakukan oleh 6 orang enumerator yang telah dilatih sebelumnya. Data primer meliputi usia anak, berat badan anak dan orang tua, tinggi badan anak dan orang tua, tingkat pendidikan, pendapatan, dan pekerjaan orang tua, serta lama waktu SBA. Lama waktu SBA ialah jumlah total waktu anak/orang tua menghabiskan waktu menonton TV, digital video disc (DVD), bermain video games, menggunakan komputer, dan handphone (HP) di rumah dalam sehari yang diukur dengan satuan menit. Wawancara mengenai lama waktu SBA, bukan hanya pada anak tetapi juga kedua orang tua (ayah dan ibu). Data lama waktu SBA dikumpulkan dalam waktu 2 
hari, saat hari sekolah/kerja (Senin-Jumat) dan hari libur (Sabtu-Minggu). Sementara untuk menjamin kualitas data, wawancara dilakukan beberapa kali pada saat orang tua anak senggang.

Sebelum pengambilan data, alat telah ditera oleh badan metrologi dengan hasil baik. Anak dan orang tua ditimbang sebanyak 3 kali menggunakan timbangan analitik dengan ketelitian 0,1 kg sedangkan tinggi badan diukur menggunakan microtoice dengan ketelitian $0,1 \mathrm{~cm}$. Anak ditimbang dan diukur tinggi badannya di sekolah sedangkan orang tua ditimbang berat dan diukur tinggi badannya di rumah saat wawancara. Lama waktu SBA diketahui menggunakan Preschool Physical Activity Questionnaire (PrePAQ) yang ditanyakan kepada orang tua subjek. Analisis data menggunakan t-test dan uji Spearman dengan tingkat kemaknaan p kurang dari 0,05. Penelitian ini telah mendapatkan izin dari komisi etik dengan nomor KE/FK/747/EC/2015. Sebelum penelitian ini dimulai, telah dilakukan validasi kuesioner yang melibatkan 30 sampel anak prasekolah di Kelurahan Muja-Muju. Saat pelatihan enumerator, telah dilakukan validasi intra dan inter rates dengan nilai 97,2-98,9\%.

\section{HASIL}

Tabel 1 menunjukkan bahwa lebih dari 50\% orang tua tergolong berpendapatan dan berpendidikan tinggi (>Rp 3.000.000/bulan dan lulus diploma/sarjana). Perbedaan yang bermakna antara kelompok gemuk dan tidak gemuk hanya pada variabel lama waktu SBA anak $(\mathrm{p}<0,05)$. Lebih lanjut, Tabel 2 menunjukkan perbedaan lama waktu SBA anak dalam kelompok gemuk dan tidak gemuk. Hanya SBA anak saat hari sekolah yang bermakna. Saat hari sekolah, rerata waktu SBA anak

Tabel 1. Karakteristik subjek penelitian

\begin{tabular}{|c|c|c|c|c|c|c|}
\hline \multirow[t]{2}{*}{ Variabel } & \multicolumn{2}{|c|}{$\begin{array}{l}\text { Gemuk } \\
(n=101)\end{array}$} & \multicolumn{2}{|c|}{$\begin{array}{l}\text { Tidak gemuk } \\
\qquad(n=101)\end{array}$} & \multirow[t]{2}{*}{$X^{2}$} & \multirow[t]{2}{*}{$\mathbf{p}$} \\
\hline & $\mathbf{n}$ & $\%$ & $\mathbf{n}$ & $\%$ & & \\
\hline \multicolumn{7}{|l|}{ Pendapatan orang tua } \\
\hline$<\operatorname{Rp} 3.000 .000$ & 44 & 43,6 & 48 & 47,5 & 0,32 & 0,58 \\
\hline$\geq \operatorname{Rp} 3.000 .000$ & 57 & 56,4 & 53 & 52,5 & & \\
\hline \multicolumn{7}{|l|}{ Pendidikan ayah } \\
\hline Tinggi (>SMA $\left.{ }^{1}\right)$ & 62 & 61,4 & 63 & 62,4 & 0,003 & 0,96 \\
\hline Rendah $(\leq \mathrm{SMA})$ & 38 & 37,6 & 38 & 37,6 & & \\
\hline \multicolumn{7}{|l|}{ Pendidikan ibu } \\
\hline Tinggi (>SMA) & 69 & 68,3 & 64 & 63,4 & 0,55 & 0,46 \\
\hline Rendah $(\leq \mathrm{SMA})$ & 32 & 31,7 & 37 & 36,6 & & \\
\hline \multicolumn{7}{|c|}{$\mathrm{SBA}^{2}$ anak hari sekolah } \\
\hline$\geq 2$ jam & 70 & 69,3 & 51 & 50,5 & 7,44 & 0,006 \\
\hline$<2$ jam & 31 & 30,7 & 50 & 49,5 & & \\
\hline \multicolumn{7}{|l|}{ SBA anak hari libur } \\
\hline$\geq 2$ jam & 58 & 57,4 & 49 & 48,5 & 1,61 & 0,20 \\
\hline$<2$ jam & 43 & 42,6 & 52 & 51,5 & & \\
\hline \multicolumn{7}{|l|}{ SBA ibu hari kerja } \\
\hline$\geq 2$ jam & 64 & 63,7 & 64 & 63,7 & 0,00 & 1,00 \\
\hline$<2$ jam & 37 & 36,6 & 37 & 36,6 & & \\
\hline \multicolumn{7}{|l|}{ SBA ibu hari libur } \\
\hline$\geq 2$ jam & 59 & 58,4 & 62 & 61,4 & 0,19 & 0,67 \\
\hline$<2$ jam & 42 & 61,4 & 39 & 38,6 & & \\
\hline \multicolumn{7}{|l|}{ SBA ayah hari kerja } \\
\hline$\geq 2$ jam & 74 & 73,27 & 67 & 66,34 & 1,15 & 0,28 \\
\hline$<2$ jam & 27 & 26,73 & 34 & 33,66 & & \\
\hline \multicolumn{7}{|l|}{ SBA ayah hari libur } \\
\hline$\geq 2$ jam & 68 & 67,33 & 69 & 68,32 & 0,02 & 0,88 \\
\hline$<2$ jam & 33 & 32,67 & 32 & 31,68 & & \\
\hline
\end{tabular}

${ }^{1} \mathrm{SMA}=$ sekolah menengah atas; ${ }^{2} \mathrm{SBA}=$ screen based activity 
Neni Pangesti, dkk: Screen based activity sebagai faktor risiko kegemukan pada anak prasekolah di Kota Yogyakarta

Tabel 2. Rerata lama waktu screen based activity (SBA) anak dan kegemukan

\begin{tabular}{|c|c|c|c|c|}
\hline Variabel & $\begin{array}{c}\text { Gemuk } \\
(\text { menit } \pm \text { SD) }\end{array}$ & $\begin{array}{c}\text { Tidak gemuk } \\
(\text { menit } \pm \text { SD })\end{array}$ & Mean diff & $\mathbf{p}$ \\
\hline SBA hari sekolah & $171 \pm 107,49$ & $124 \pm 79,21$ & $\begin{array}{c}-47,47 \\
(-73,69-(-) 21,26)\end{array}$ & $0,0005^{*}$ \\
\hline SBA hari libur & $152 \pm 118,75$ & $115 \pm 86,42$ & $\begin{array}{c}-36,54 \\
(-65,4-(-) 7,7)\end{array}$ & 0,21 \\
\hline
\end{tabular}

*t-test, bermakna $(\mathrm{p}<0,05)$

Tabel 3. Rerata lama waktu screen based activity (SBA) orang tua dan kegemukan anak

\begin{tabular}{ccccc}
\hline Variabel & Gemuk & Tidak gemuk & Mean diff & p \\
\cline { 2 - 3 } (menit \pm SD) & (menit \pm SD) & & Mn \\
SBA ibu hari kerja & $186 \pm 149,23$ & $158 \pm 120,69$ & $\begin{array}{c}27,92 \\
(-9,74 ; 65,59)\end{array}$ & 0,14 \\
SBA ibu hari libur & $179 \pm 153,54$ & $154 \pm 122,01$ & $\begin{array}{c}24,36 \\
(-14,13 ; 62,84)\end{array}$ & 0,21 \\
SBA ayah hari kerja & $202 \pm 159,02$ & $188 \pm 158,45$ & $\begin{array}{c}-14,31 \\
(-58,35-29,74) \\
1,3\end{array}$ & 0,52 \\
SBA ayah hari libur & $189 \pm 168,61$ & $188 \pm 141,57$ & $(-41,9 ; 44,49)$ & 0,95 \\
\hline
\end{tabular}

kelompok gemuk lebih lama 48 menit. Berdasarkan uji Spearman, SBA anak saat hari libur berhubungan dengan SBA saat hari sekolah dengan besarnya korelasi sedang. Semakin lama waktu SBA anak saat hari libur, maka semakin lama pula SBA saat hari sekolah.

Perbedaan retata lama waktu SBA orang tua antara kelompok gemuk dan tidak gemuk tidak bermakna secara statistik. Saat hari kerja, ibu dari kelompok gemuk menghabiskan waktu 28 menit lebih lama dibanding kelompok tidak gemuk sedangkan saat hari libur, lama waktu SBA ibu kelompok tidak gemuk menghabiskan waktu 24 menit lebih pendek dibanding kelompok gemuk. Sementara pada ayah, saat hari kerja kelompok gemuk menghabiskan waktu 15 menit lebih lama dan hari libur menghabiskan waktu 1 menit lebih lama dibanding kelompok tidak gemuk (Tabel 3).

\section{BAHASAN}

Penelitian ini menunjukkan bahwa pada saat hari sekolah, SBA kelompok gemuk lebih lama 48 menit dibanding kelompok tidak gemuk. Aktivitas kurang gerak seperti menonton TV dan bermain video games menjadi kegiatan favorit sepulang sekolah. Gawai (gadget) menggantikan lingkungan alami anak, seperti interaksi keluarga agar anak tumbuh dengan belajar dan bermain
(13). Screen based activity (utamanya TV) dihubungkan dengan rendahnya konsumsi sayur dan buah serta tingginya konsumsi camilan tinggi kalori, makanan cepat saji (8), dan minuman kemasan tinggi gula (9). Semakin tinggi SBA pada anak, akan menekan perasaan kenyang, sehingga menyebabkan makan berlebih. Saat hari libur, SBA anak berkaitan dengan rerata SBA dan SBA saat hari sekolah. Kemungkinan hal ini disebabkan oleh persepsi orang tua yang menganggap bahwa saat hari sekolah dan sehari-hari anak sudah terlalu banyak menghabiskan waktu menggunakan gawai. Oleh karena itu, orang tua membatasi SBA anak saat hari libur dan mengajak anak melakukan aktivitas di luar rumah (5).

Etiologi kegemukan anak sangat kompleks. Penyebabnya ialah faktor genetik, sosial ekonomi, dan lingkungan (1). Pengaruh lingkungan melalui ketidakseimbangan antara pola makan dan aktivitas fisik (14) juga pesatnya perkembangan industri dan media. Pola makan yang menyebabkan kegemukan ialah mengonsumsi makanan melebihi kebutuhan serta mengonsumsi makanan tinggi energi, lemak, karbohidrat sederhana dan rendah serat. Penyebab anak malas beraktivitas fisik dan memilih SBA adalah lapangan bermain yang terbatas, fasilitas fisik yang tidak memadai, dan kemajuan teknologi (15). Industri 
makanan mempengaruhi dalam hal penyediaan makanan dengan gula dan lemak tersembunyi, makanan tinggi kalori, peningkatan gerai restoran, dan makanan cepat saji. Iklan makanan memberi pengaruh negatif pada anak untuk memilih makanan tidak sehat dibanding makanan sehat (1). Kegemukan pada anak merupakan masalah serius karena berisiko akan berlanjut hingga usia dewasa. Selain itu, kegemukan merupakan faktor risiko terjadinya berbagai penyakit metabolik dan degeneratif seperti penyakit kardiovaskuler, diabetes mellitus, dan kanker. Kegemukan anak dapat menyebabkan masalah kesehatan yang merugikan kualitas hidup anak seperti gangguan pertumbuhan tungkai kaki, gangguan tidur, sleep apnea (henti napas sesaat), dan gangguan pernafasan lainnya (15).

Seorang anak berisiko obes jika memiliki keluarga yang gemuk. Perilaku orang tua akan mempengaruhi pilihan makanan dan aktivitas fisik pada anak (1). Indeks massa tubuh (IMT) merefleksikan gaya hidup, termasuk aktivitas fisik, perilaku makan, dan kurang gerak (16). Indeks massa tubuh ayah merupakan prediktor yang signifikan pada berat badan anak (17). Sementara ibu yang gemuk kurang berpartisipasi dalam aktivitas yang memerlukan gerak fisik dan lebih suka melakukan aktivitas kurang gerak seperti menonton TV dengan anak mereka (18). Apabila dilihat berdasarkan jenis kelaminnya, maka anak perempuan lebih suka menonton TV sebagai aktivitas kurang gerak sedangkan anak lakilaki lebih suka bermain game komputer (19). Dalam tradisi Indonesia, seperti halnya China, ada persepsi anak gemuk sebagai tanda sehat dan makmur. Selain itu, struktur keluarga juga berpengaruh penting dalam kegemukan anak. Anak yang tinggal dengan keluarga besar lebih berisiko gemuk dibanding anak dengan keluarga inti. Anak yang dibesarkan oleh kakek neneknya juga lebih rentan gemuk dibanding yang diasuh orang tuanya (20).

Anak yang berasal dari keluarga sosial ekonomi tinggi berisiko 3,5 kali mengalami kegemukan dibanding ekonomi rendah (21). Namun, ada pula penelitian yang menyatakan penghasilan orang tua tidak berhubungan dengan SBA anak (22). Sementara itu, penelitian di Irlandia menyatakan bahwa anak yang berasal dari sosial ekonomi tinggi akan lebih sedikit menghabiskan waktu di depan TV dan anak dari sosial ekonomi rendah akan mengonsumsi lebih banyak kalori (23). Sosial ekonomi orang tua juga mempengaruhi kegemukan anak. Selain penghasilan, status sosial ekonomi dapat dilihat melalui tingkat pendidikan. Pendidikan orang tua yang tinggi menjadi faktor protektif obesitas anak. Anak berlatar belakang orang tua berpendidikan rendah menjadi gemuk karena rendahnya pengetahuan tentang pemilihan makanan, keseimbangan energi, dan mengontrol berat badan. Anak dari ibu berpendidikan rendah, lebih sering memiliki TV di kamar dan melakukan SBA melebihi batasan (16). Semakin lama waktu ibu bekerja cenderung berhubungan negatif dengan aturan keluarga mengenai batasan menonton TV (24).

Bentuk aktivitas kurang gerak lainnya adalah transportasi. Saat ini, anak sekolah diantar menggunakan mobil. Anak dari keluarga dengan akses transportasi, TV, dan komputer lebih mudah, akan lebih kurang gerak. Anak dengan monitoring orang tua dan batasan waktu SBA menjadi lebih aktif bergerak dan mengonsumsi makanan sehat (17). American Academy of Pediatrics merekomendasikan waktu penggunaan SBA bagi anak prasekolah 1-2 jam/hari. Waktu penggunaan SBA akan menggantikan aktivitas yang bermanfaat untuk pertumbuhan dan perkembangan seperti membaca, aktivitas fisik, dan bermain imajinasi (25).

Anak prasekolah biasanya menggunakan smartphone saat di rumah atau perjalanan jauh. Selain itu, beberapa orang tua menyebutkan bahwa mereka menggunakan smartphone untuk membujuk anak saat waktu makan tiba. Walaupun orang tua menyatakan kekhawatiran mengenai masalah kesehatan, kesepian, dan terisolasi dari lingkungan sekitar akibat penggunaan smartphone. Namun, orang tua menganggap penggunaan smartphone oleh anak merupakan konsekuensi berada di zaman digital (26). Sikap individu terbentuk secara cepat melalui informasi dari media elektronik, terutama melalui iklan makanan yang ditawarkan melalui TV kabel dan website. Iklan TV dapat mempengaruhi anak usia prasekolah dalam memilih makanan (27). Iklan makanan memberi pengaruh negatif pada anak untuk memilih makanan tidak sehat dibanding makanan sehat (1). Anak cenderung memilih makanan yang mereknya mereka kenal dibanding yang tidak. Anak 
yang menonton iklan TV mempercayai bahwa fast food lebih sehat daripada makanan rumah. Anak usia 2-8 tahun cenderung memilih makanan yang mereknya diiklankan saat menonton TV walaupun dengan paparan iklan singkat. Tiga dari 4 jenis makanan yang diminta oleh anak merupakan produk makanan yang dilihat di TV. Marketing dan periklanan membidik anak yang sedang online dengan teknik yang interaktif. Situs ini menawarkan berbagai hal menarik, seperti game, kuis, video klip, desktop, dan wallpaper produk mereka, serta hadiah (28).

Tersedianya TV di kamar tidur anak merupakan indikator yang baik bagi prevalensi kegemukan anak. Anak dengan TV di kamar berisiko 1,3 kali lebih gemuk dibanding yang tidak memiliki TV di kamar. Selain itu, anak dengan televisi di kamar akan menghabiskan waktu 4,6 jam/minggu untuk menonton TV/video (29). Televisi di kamar tidur juga dihubungkan dengan kurang tidur yang berakibat pada peningkatan risiko kegemukan (30). Anak usia 3-4 yang TV di rumahnya menyala secara konstan 2 kali lipat akan menonton TV $>2$ jam/hari dibanding teman yang TV di rumahnya tidak menyala sepanjang waktu (31).

Hubungan SBA anak dan orang tua disebabkan oleh perilaku SBA orang tua mendukung perilaku yang sama pada anak mereka (32). Perilaku orang tua akan mempengaruhi kebiasaan anak dan menjadi contoh dalam kebiasaan individu (29). Namun, hasil pada penelitian ini tidak terbukti bahwa SBA orang tua mempengaruhi SBA anak, maupun kegemukan anak. Perbedaan lama waktu SBA orang tua pada kelompok gemuk dibanding kelompok tidak gemuk tidak bermakna. Hal ini kemungkinan disebabkan oleh pengetahuan orang tua tentang penggunaan media sangat terbatas dan hanya sebagian yang menghabiskan waktu sepanjang hari bersama anak (31). Penyebab lain adalah orang tua mengestimasi lama waktu SBA lebih kecil dari yang sebenarnya karena mengetahui bahwa SBA merupakan kontributor kegemukan (7). Penelitian lain menyatakan bahwa SBA orang tua berhubungan positif dengan SBA anak (22). Anak dengan orang tua yang menonton TV $>2$ $\mathrm{jam} /$ hari cenderung menonton $\mathrm{TV}>2 \mathrm{jam} /$ hari. Penelitian tersebut menegaskan mengenai waktu menonton TV ibu lebih kuat sebagai prediktor waktu menonton TV anak dibanding ayah (12). Hal ini mengindikasikan bahwa ibu berperan penting sebagai panutan perilaku menonton TV anak. Penelitian lain juga menyatakan bahwa anak yang orang tuanya menghabiskan waktu 1 jam melakukan multigawai, maka anak akan berisiko 34 kali multigawai selama lebih dari 1 jam (33). Minimnya aturan orang tua tentang menonton TV dan adanya play station (PS) dihubungkan dengan kurangnya aktivitas luar ruang (34). Orang tua anak prasekolah hanya memperhatikan isi tontonan anak mereka tapi tidak memperhatikan waktu penggunaan SBA yang berisiko kegemukan anak. Mereka menganggap bahwa TV berguna sebagai alat pengasuhan anak dan mereka menggunakannya sebagai strategi menghadapi banyak anak (5).

Kegemukan anak diprediksi kuat karena kegemukan orang tua dan hal ini dimulai sejak anak berusia 4-6 tahun (35). Selain itu, anak yang menghabiskan lebih banyak waktu dalam aktivitas kurang gerak seperti melakukan SBA, cenderung lebih berat dan berisiko overweight (13). Kekuatan penelitian ini adalah menganalisis besar risiko lama waktu screen based activity (SBA) anak dan SBA orang tua pada kejadian kegemukan pada anak prasekolah. Jumlah subjek cukup besar dan mewakili daerah di Kota Yogyakarta sehingga dapat menggambarkan kejadian kegemukan anak prasekolah. Saat memberikan informed consent, peneliti menyebutkan lama waktu wawancara dan menyesuaikan dengan waktu senggang responden. Selain itu, peneliti juga memberi waktu yang cukup bagi responden untuk mengingat (wawancara selama 30 menit). Data SBA pada penelitian ini hanya menggunakan 1 kali recall SBA karena ingin menggali kebiasaan anak menggunakan gawai dalam sehari. Akan tetapi, kebiasaan anak prasekolah dipengaruhi oleh berbagai faktor. Selain kebiasaan penggunaan SBA orang tua, anak prasekolah pada saat hari libur lebih banyak menghabiskan waktu di luar rumah sehingga SBA saat hari libur tidak bermakna.

\section{SIMPULAN DAN SARAN}

Lama waktu SBA anak saat hari sekolah menjadi faktor risiko kegemukan sedangkan lama waktu SBA saat hari libur dan orang tua tidak meningkatkan peluang terjadinya kegemukan anak prasekolah di Kota Yogyakarta. Dalam upaya menurunkan SBA anak saat 
hari sekolah yang menjadi faktor risiko kegemukan, perlu sosialisasi kepada orang tua dan guru mengenai batasan lama waktu penggunaan multigawai sebesar 2 jam/hari. Sosialisasi ini dilakukan melalui penyebaran leaflet dan poster. Penelitian selanjutnya dengan durasi SBA sebaiknya menggunakan 3 kali recall aktivitas agar lebih menggambarkan SBA anak yang sebenarnya.

\section{Pernyataan konflik kepentingan}

Penulis menyatakan tidak ada konflik kepentingan dengan pihak-pihak yang terkait dalam penelitian ini.

\section{RUJUKAN}

1. Procter KL. The aetiology of childhood obesity : a review. Nutr Res Rev [series online] 2007 [cited 2015 Feb 7];20:29-45. Available from: http://www.ncbi.nlm.nih.gov/ pubmed/19079859

2. Riskesdas. Badan Penelitian dan Pengembangan Kesehatan. [series online] 2013 [cited $2015 \mathrm{Feb}$ 7]. Available from: www.depkes.go.id/resources/download/general/Hasil\%20 Riskesdas\%202013

3. Riskesdas. Badan Penelitian dan Pengembangan Kesehatan. [series online] 2010 [cited $2015 \mathrm{Feb} 7$ ]. Available from: www.diskes.baliprov.go.id/files/subdomain/diskes/.../ RISKESDAS\%202010.pdf

4. Dinas Kesehatan Provinsi DIY. Keputusan Kepala Dinas Kesehatan Provinsi DIY Tentang Rencana Strategis Dinas Kesehatan Provinsi DIY Tahun 2009 - 2013 [series online] 2013 [cited 2015 Feb 7]. Available from: http://dinkes. jogjaprov.go.id/berita/detil_berita/129-rencana-strategiskesehatan-provinsi-diy-20092013

5. He M, Piche L, Beynon C, Harris S. Screen-related sedentary behaviors: children's and parents' attitudes, motivations, and practices. J Nutr Educ Behav 2010;42(1):17-25.

6. Tremblay MS, Willms JD. Is the Canadian childhood obesity epidemic related to physical inactivity? Int J Obes Relat Metab Disord 2003;27(9):1100-5.

7. Sisson SB, Shay CM, Broyles ST, Leyva M. Televisionviewing time and dietary quality among U.S. children and adults. AMEPRE 2012;43(2):196-200.

8. Pearson N, Biddle SJH. Sedentary behavior and dietary intake in children, adolescents, and adults. AMEPRE 2011;41(2):178-88.

9. Dulloo AG, Antic V, Yang Z, Montani J. Propellers of growth trajectories to obesity and the metabolic syndrome. Int J Obes 2006;30:3-5.

10. Rodrigues-Oliveros G, Haines J, Ortega-altamirano D, Power E, Taveras EM, Gonzales-Unzaga MA, et al. Obesity determinants in mexican preschool children : parental perceptions and practices related to feeding and physical activity guadalupe rodr. ARCMED 2011;42:532-9.

11. Andersen RE, Crespo CJ, Bartlett SJ, Cheskin LJ, Pratt M. relationship of physical activity and television watching with body weight and level of fatness among children and nutrition examination survey. JAMA 1998;279(12):1822.

12. Jago R, Stamatakis E, Gama A, Carvalhal IM, Nogueira H, Rosado V, et al. Parent and child screen-viewing time and home media environment. AMEPRE 2012;43(2):150-8.

13. Sharlin J, Edelstein S. Life cycle nutrition life cycle nutrition. first. USA: Jones and Barlett; 2010.

14. WHO. Understanding how overweight and obesity develop. [series online] 1998 [cited 2015 Feb 7]. Available from: http://www.who.int/nutrition/publications/obesity/ WHO_TRS_894/en/

15. Kementerian Kesehatan RI. Pedoman pencegahan dan penanggulangan kegemukan dan obesitas pada anak sekolah. [series online] 2012 [cited 2015 Feb 7]. Available from: https://id.scribd.com/doc/179494332/Obesitas-pdf.

16. Wijtzes AI, Jansen W, Kamphuis CB, Jaddoe VW, Moll HA, Raat $\mathrm{H}$, et al. Increased risk of exceeding entertainment-media guidelines in preschool children from low socioeconomic background: the Generation R Study. Prev Med 2012;55(4):325-9.

17. Lloyd AB, Lubans DR, Plotnikoff RC, Collins CE, Morgan PJ. Maternal and paternal parenting practices and their influence on children's adiposity, screen-time, diet and physical activity. Appetite 2014;79:149-57.

18. Gittner LS. Obesity Prevention in Children from Birth to Age 5. Primary Prevention Insights 2014;4:1-9.

19. Melkevik O1, Torsheim T, Iannotti RJ, Wold B. Is spending timen screen-based sedentary behaviors associated with less physical activity : a cross national investigation. Int $\mathrm{J}$ Behav Nutr Phys Act 2010;21;7:46.

20. Zong X, Li H, Zhang Y. Family-related risk factors of obesity among preschool children : results from a series of national epidemiological surveys in China. BMC Public Health 2015;15(927):1-11.

21. Kourlaba G, Kondaki K, Liarigkovinos T, Manios Y. Factors associated with television viewing time in toddlers and preschoolers in Greece : the GENESIS study. J Public Health (Bangkok) 2009;31(2):222-30.

22. Carson V, Janssen I. Associations between factors within the home setting and screen time among children aged $0-5$ years : a cross-sectional study. BMC Public Health, (2012);12(1):1-8.

23. Department of Children and Youth Affairs. Cohort growing up in Ireland key findings : infant cohort. [series online] 2013 [cited 2015 Feb 7]. Avalable from: URL: http: www. growingup.ie/ 
24. Anderson PM. Economics and Human Biology Parental employment, family routines and childhood obesity. Economics and Human Biology 2012;10(4):340-51.

25. Duursma E, Augustyn M, Zuckerman B. Reading aloud to children: the evidence. Arch Dis Child 2008;93(7):554-7.

26. Genc Z. Parents' Perceptions about the mobile technology use of preschool aged parents' perceptions about the mobile technology use of preschool aged children. Procedia Social and Behavioral Sciences 2014;55-60.

27. American Academy of Pediatrics. Media use by children younger than 2 years. [series online] 2011 [cited $2015 \mathrm{Feb}$ 7]. Available from: URL: https://pediatrics.aappublications. org/content/128/5/1040

28. Mazur A, Winnicki IR. Obesity and media. in child and adolescent obesity. [series online] 2015 [cited 2015 Feb 7]. Available from: URL: https://ebook.ecog-obesity.eu

29. Nanney MS. Chapter 19 and elementary school-age years. [series online] 2004 [cited $2015 \mathrm{Feb}$ 7]. Available from: https://quizlet.com/90609700/chapter-19-the-school-agechild-flash-cards/

30. Minnesota Dept. of Health. Fast forward to better healt. [series online] 2010 [cited $2015 \mathrm{Feb} 7$ ]. Available from:
URL: https://www.health.state.mn.us/cdrr/obesity/ tvviewingfastforwardreport.pdf

31. Vandewater EA, Rideout VJ, Wartella EA, Huang X, Lee JH. Digital childhood : electronic media and technology use among infants, toddlers, and preschoolers. Pediatrics 2007;119(5):e1006-15.

32. Kourlaba G, Kondaki K, Liarigkovinos T, Manios Y. Factors associated with television viewing time in toddlers and preschoolers in Greece: the GENESIS study. J Public Health (Oxf) 2009;31(2):222-30.

33. Jago R, Sebire SJ, Lucas PJ, Turner KM, Bentley GF, Fox KR, et al. Parental modelling, media equipment and screenviewing among young children: cross-sectional study. BMJ Open 2013;3(4):1-6.

34. Spurrier NJ, Magarey AA, Golley R, Curnow F, Sawyer MG. Relationships between the home environment and physical activity and dietary patterns of preschool children: a cross-sectional study. International Journal of Behavioral Nutrition and Physical Activity 2008;5:31.

35. Reilly JJ, Armstrong J, Dorosty AR, Emmett PM, Ness A, Sherriff A. Early life risk factors for obesity in childhood : cohort study. BMJ 2005;330(7504):1357. 